\title{
Worker Reactions to Electrochromic and Low e Glass Office
}

\section{Windows}

\section{Hedge $A^{*}$ and Nou D \\ Department of Design and Environmental Analysis, Cornell University, USA}

*Corresponding author: Alan Hedge, Department of Design and Environmental Analysis, Cornell University, Ithaca NY 14853, USA, Email: ah29@cornell.edu

\section{Research Article}

Volume 2 Issue 4

Received Date: July 06, 2018

Published Date: July 23, 2018

DOI: $10.23880 /$ eoij-16000166

\section{Abstract}

Occupant surveys about the daylight and the visual environment effects of work, satisfaction, health and well-being, were conducted in 5 office buildings with electrochromic glass $(n=268)$ and 2 office buildings with low-e glass (n=-44). Online surveys were administered to volunteer participants. Results showed that subjective reports of eyestrain, headaches, lighting quality satisfaction, window glass lighting quality, and alertness were significantly better for the electrochromic glass buildings. No significant differences between building types were found for daylight glare, daylight quality, mood, energy levels, health and well-being, self-rated productivity, and work quality. Findings show that electrochromic glass can improve indoor light quality that benefits occupant comfort and wellness.

Keywords: Electrochromic Glass; Office Windows; Daylight; Office Lighting; Eyestrain; Visual Comfort; Work Quality

\section{Introduction}

Current sustainable building ratings systems, such as LEED or WELL, reward building designs that use windows to facilitate daylight penetration into the buildings. In the LEED system, windows in regularly occupied areas of a building are important for daylight exposure and to give occupants external views that provide a connection between the indoors and the outdoors [1,2]. The WELL building rating system, Version 2, states that "Light is the main driver of the visual and circadian systems" and it favors projects that "design spaces to integrate daylight into indoor environments so that daylight may be used for visual tasks along with electric lighting [3,4]. It also provides individuals with a connection to outdoor spaces through view windows" (WELL v2, CONCEPTS / LIGHT / FEATURE L05, Enhanced Daylight Access, 2018). Similarly, Fitwel (2018) awards points for buildings that "Provide natural daylight in a majority of workspace" and "Provide views of nature to the outside from a majority of workstations." Fitwel recognizes that windows can be a source of glare so also awards credit for providing "Operable shading of all workspace windows."

Windows allow daylight to enter buildings and daylight plays an important role in human health. Daylight improves vitamin D synthesis and synchronizes circadian rhythms [5,6]. Window views to the outdoors can improve health, especially where views are of natural scenes with trees and vegetation [7]. Looking through a window to a view of nature reduces nervousness/anxiety levels compared to a view to a cityscape or no window view [8]. Heschong [9] showed that performance in a call center was $6-7 \%$ faster when workers had a window view. Leather, et al. [10] found that access to daylight can increase job satisfaction and outdoor views can reduce job stress. Perhaps not surprisingly, Aries found that people overwhelmingly prefer working near windows [11]. However, daylight intensity through windows varies throughout the day and from day to day throughout the year. Also, window orientation affects daylight penetration and bright daylight can create direct and 
reflected glare problems for occupants, especially those sitting at the south and the west facing façades [12].

Some $50 \%$ of daylight comprises of infrared wave lengths (heat). Sitting close to a window on a hot and sunny day can be both visually uncomfortable from glare, and thermally uncomfortable from solar heat gain. Glare can also increase symptoms of computer vision syndrome (CVS), characterized by (symptoms of eyestrain, tired eyes, irritation, redness, blurred vision, and double vision among office workers, especially those near to windows $[13,14]$. To combat solar heat and glare, low emissivity (low-e) glass coatings are often used in for commercial building façades to reduce solar heat gains and/or losses through windows, and low-e glass can be tinted to reduce glare. However, low-e glass still allows some infrared light (solar heat gain) and it has a fixed light transmittance. To mitigate these problems internal or external blinds often are used, but the deployment of blinds diminishes or eliminates access to outside views.

Unlike low-e glass, electrochromic glass (EC) is electrically controlled to change its light transmittance, from a clear state, with almost $60 \%$ light transmittance, to varying darker states (down to only 1\% light transmittance) to reduce daylight glare and solar heat gain without blocking a view to the outside (Figure 1). Infrared light (solar heat) comprises wavelengths from 0.70-1 micron, and as this figure shows, these wavelengths are filtered out in tint states 3 and 4, which save on the usage of air-conditioning [15]. In these tint states, most of the transmitted visible light is in the blue wavelengths (0.45-0.49 microns) and green wavelengths (0.49-0.57 microns). In all tint states, there is a view through the electrochromic glass, but the greater the tint state, the bluer the appearance of the window.

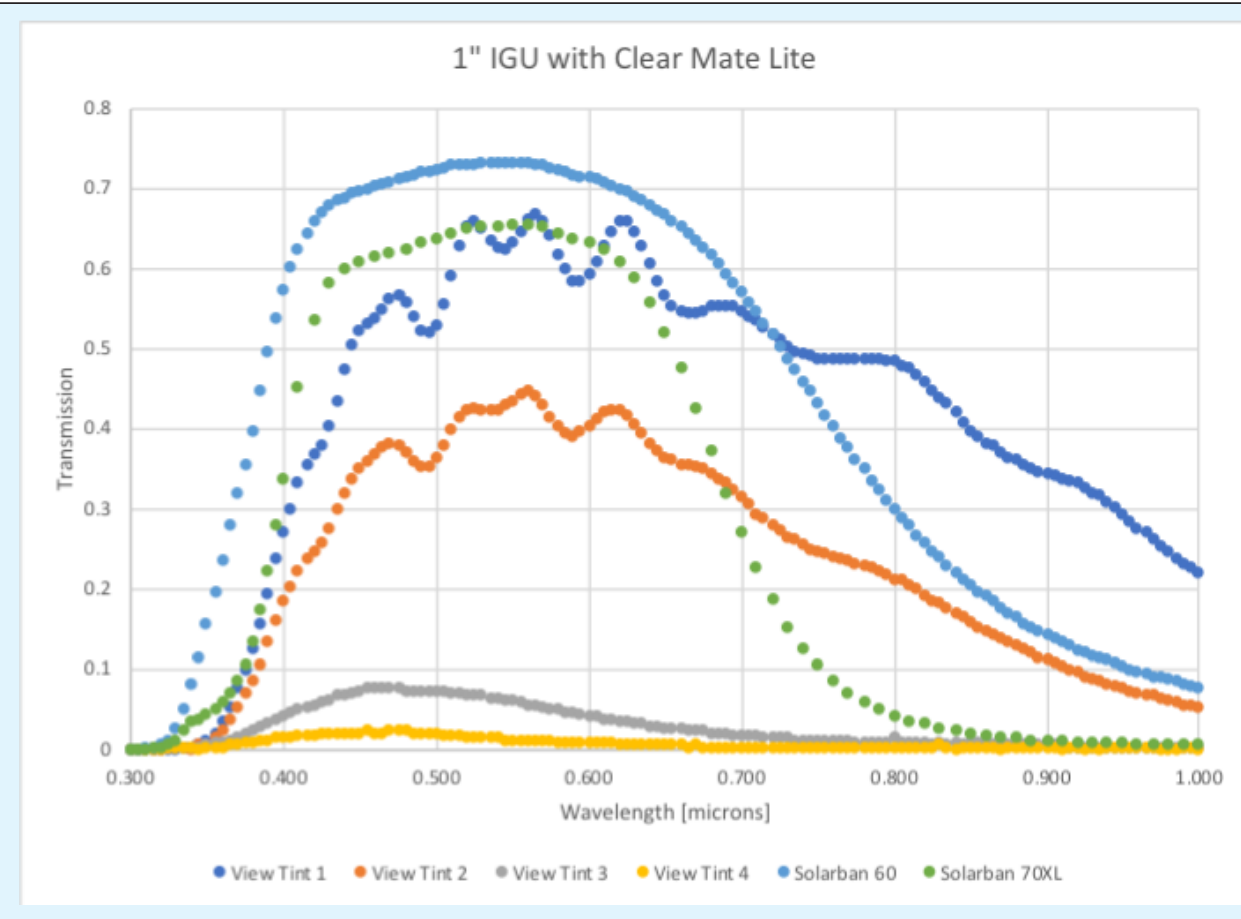

Figure 1: Light transmittance spectra for each of the 4 tint states of a 1" thick dynamic insulating glass unit (IGU) that contains an electrochromic coating to switch between clear and tinted on demand, and 2 types of low-e glass (Solarban 60 and Solarban 75).

Intrinsically photosensitive retinal ganglion cells (ipRGCs) respond to blue light, with peak absorption at 0.48 microns, and they help to synchronizing circadian rhythms to the 24-hour light/dark cycle and they have involvement in the pupillary light reflex response as light levels change [16]. Mills, Tomkins, and Schlangen [17] found significantly less fatigue and daytime sleepiness, improved alertness and work performance, greater vitality and better mental health in a shift-working call center with high correlated color temperature $(17000 \mathrm{~K})$ fluorescent lights with greater blue light wavelengths that can stimulate ipRGCs. There is a growing body of evidence that blue light can improve mood, alertness, memory, cognitive performance and aids in coping with any effect of a post-lunch dip on the EEG and in performance [1823]. Hedge and Nou [24] found that electrochromic glass 


\section{Ergonomics International Journal}

also may improve worker visual comfort and satisfaction, and reduce symptoms associated with CVS.

The present study compared reactions of office workers to their visual environment in buildings with façades with either traditional low-e glass (LeG) or electrochromic glass (EC). Given the evidence reviewed we hypothesized that in office buildings with EC, opinions of the visual environment, lighting satisfaction, lighting performance, CVS, alertness, and sleep quality will be better than for workers in office buildings with LeG.

\section{Methods}

\section{Survey Samples}

The study sample comprised a 268 volunteer office workers was surveyed from in 5 office buildings with EC and 45 volunteer office workers in 2 buildings with LeG. All office buildings were in North America (Salt Lake City, Utah; Gainsville, Florida; Seattle, Washington; Charleston, West Virginia; and Toronto, Canada) (Table 1).

\begin{tabular}{|c|c|c|c|}
\hline Site & $\begin{array}{c}\text { Area } \\
\text { (sqft) }\end{array}$ & $\begin{array}{c}\text { Participa } \\
\text { nts }\end{array}$ & $\begin{array}{c}\text { Est. Salary with } \\
\text { Benefits }\end{array}$ \\
\hline $\begin{array}{c}\text { Ontario, } \\
\text { CA }\end{array}$ & 37,000 & 50 & $\$ 87,500$ \\
\hline Boone, NC & 18,000 & 54 & $\$ 112,000$ \\
\hline $\begin{array}{c}\text { Gainesvill } \\
\text { e, FL }\end{array}$ & 15,500 & 105 & $\$ 93,000$ \\
\hline SLC, UT & 252,000 & 25 & $\$ 81,250$ \\
\hline $\begin{array}{c}\text { Seattle, } \\
\text { WA }\end{array}$ & 89,000 & 35 & $\$ 70,000$ \\
\hline
\end{tabular}

Table 1: Summary of the sample characteristics.

\section{Survey Questionnaires}

An online survey questionnaire (Google Forms) was designed to evaluate occupant responses for the following factors: Comfort, Satisfaction, Performance, Productivity, Alertness, Sleep, Health, and Well-being. Each participating company was allowed make minor modifications to their survey, but not the core questions. All surveys were administered electronically over the internet (Google Docs) in September 2017. Respondents were given 2 weeks to complete their survey.

\section{Statistical Analysis}

All survey data was computer coded and analyzed using multivariate statistical software (PSPP 1.01) to compare response for respondents in the EC and LeG buildings. The criterion of significance for all statistical tests was $\mathrm{p}<0.05$.

\section{Results}

\section{Sample Demographics}

There was no significant difference in the distribution of gender for respondents and $47.4 \%$ were male in the EC offices and $29.5 \%$ were male in the LeG offices. There was no significant difference in the tenure profile of respondents and most respondents had worked in their building for one year or less. (67.8\% in EC offices; 86.6\% in LeG offices). Most respondents (94.6\%) had worked in various other types of office buildings prior to the survey. There was no significant difference in respondent's use of corrective lens and $39.0 \%$ in the EC offices and $43.6 \%$ in the LeG offices wore no corrective lens. There was no significant difference in the ages of respondents in the EC and LeG samples (Table 2).

\begin{tabular}{|c|c|c|}
\hline Age (years) & EC (n=266) & LeG $(\mathbf{n = 4 4 )}$ \\
\hline$<=20-30$ & $37.6 \%$ & $38.7 \%$ \\
\hline $31-40$ & $27.8 \%$ & $25.0 \%$ \\
\hline $41-50$ & $13.5 \%$ & $15.9 \%$ \\
\hline $51-60$ & $21.0 \%$ & $20.4 \%$ \\
\hline
\end{tabular}

Table 2: Respondent ages in the EC and LeG buildings.

\section{Window Proximity}

EC reduces the solar gain of heat through windows and consequently more people should be able to comfortably sit closer to the windows. As predicted, there was a significant difference in window proximity between EC and LeG buildings $(\chi 2(3, N=312)=57.180, p=0.000 \varnothing=$ .394), and three times more workers in the EC buildings sat within 10 feet of a window compared to the LeG buildings (Figure 2). 


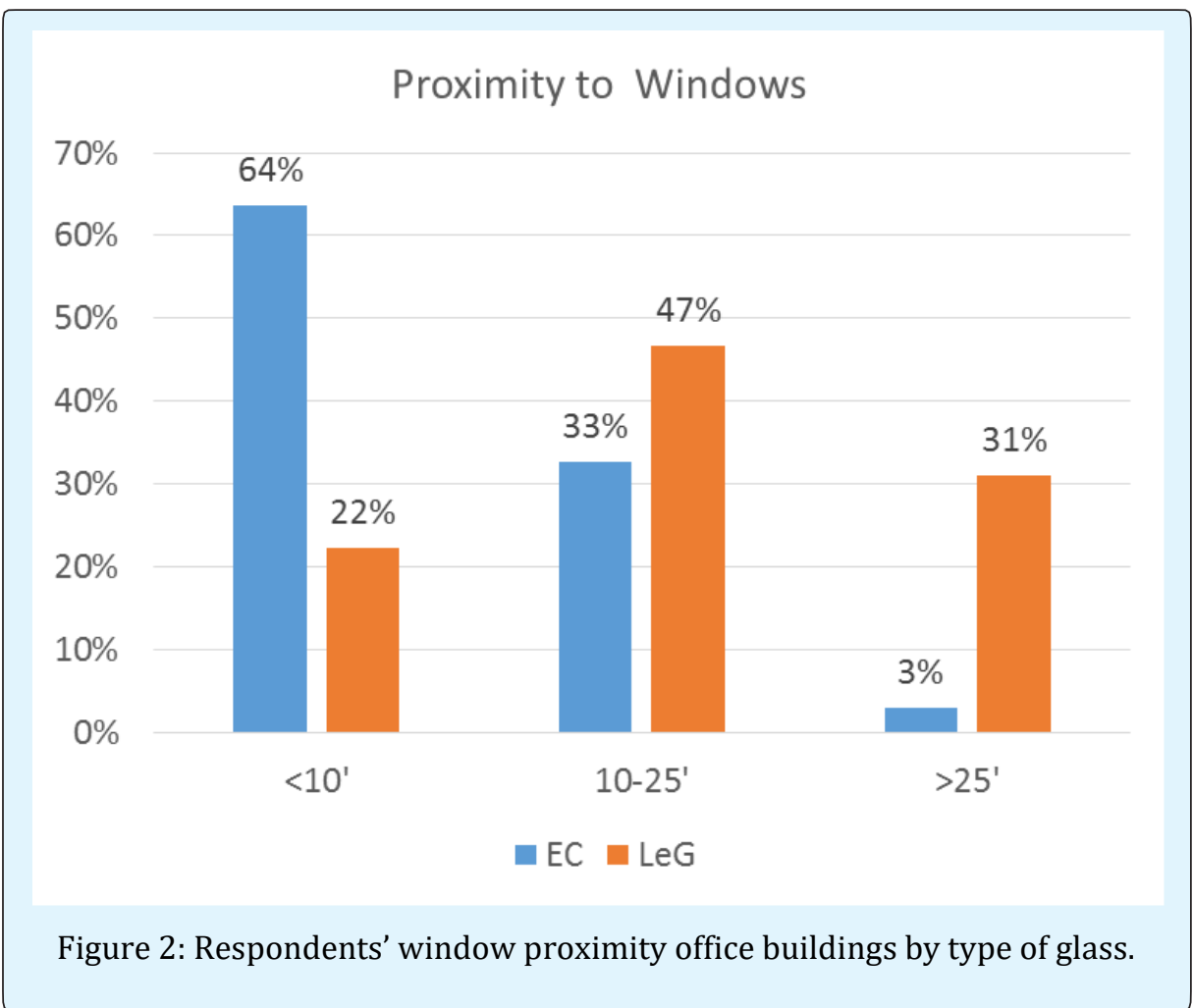

\section{Sun View}

There was a significant difference between buildings with the EC and those with LeG $(\chi 2(4, \mathrm{~N}=312)=10.320$, $\mathrm{p}$ $=0.035 \varnothing=.179)$, and twice as many workers in the LeG

buildings than in the EC buildings said that they don't see any sun through the windows from their office desk (Figure 3).

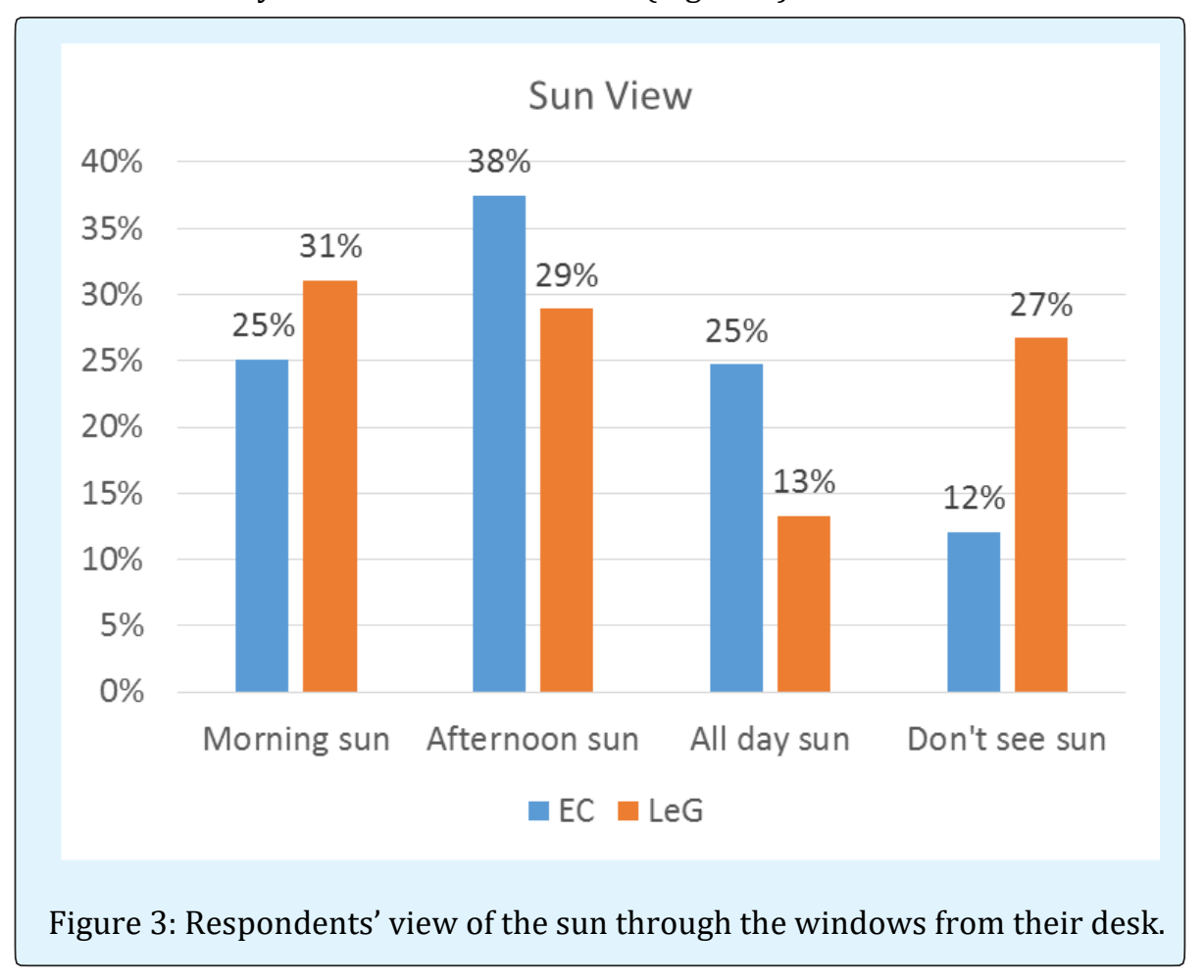




\section{Daylight Quality}

Respondents were asked to rate the quality (brightness, color) of the daylight in their office, and there was a significant difference in ratings of daylight quality between the EC and LeG buildings $(\chi 2(3, N=311)=$
18.281, $\mathrm{p}=0.000 \varnothing=.236$ ), and as shown in Figure 4, more respondents in the EC buildings said that daylight was 'excellent' or 'really good' $(70 \%)$ than compared with those in the LeG buildings (39\%) (Figure 4).

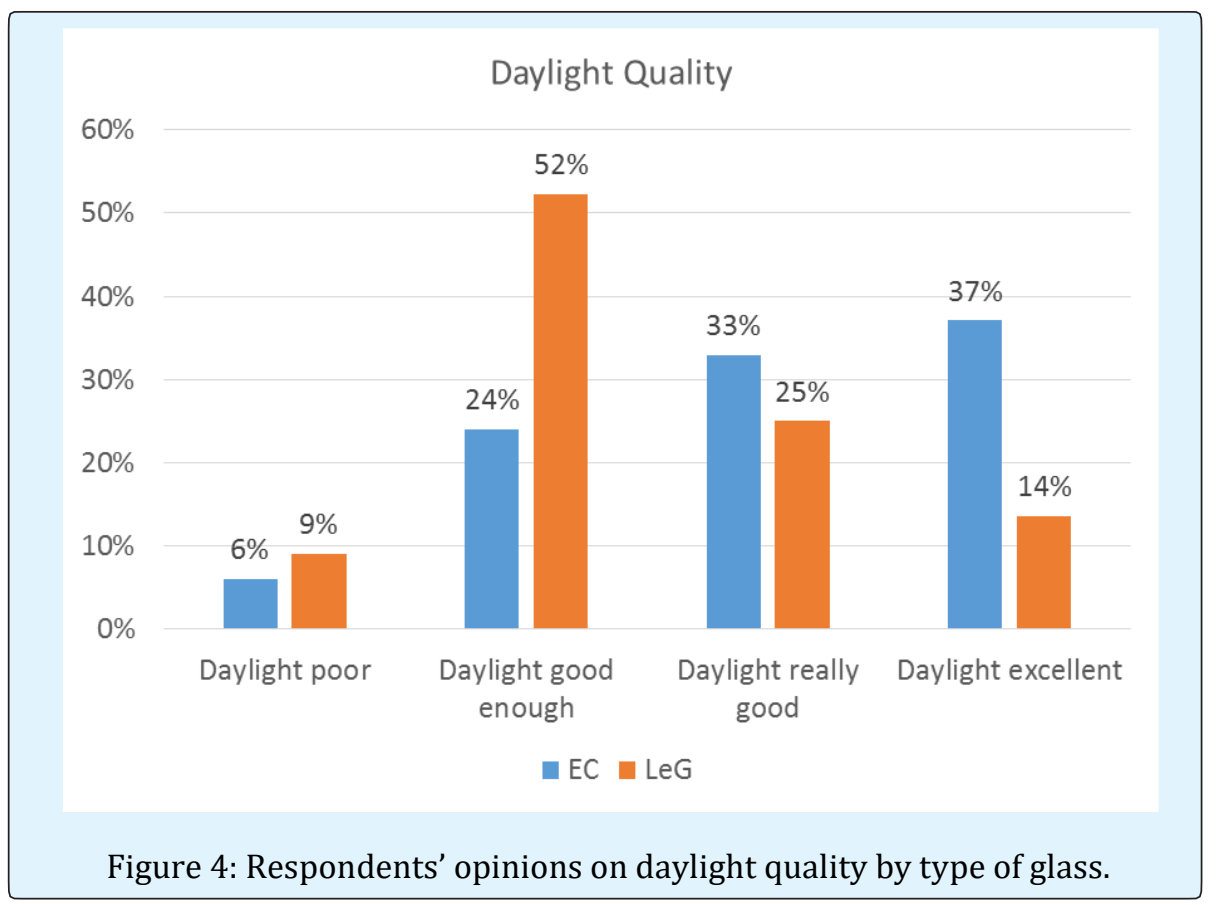

\section{Overall Lighting Quality}

There was a significant difference in ratings of overall lighting quality between buildings with the $\mathrm{EC}$ and those with LeG $(\chi 2(5, N=310)=13.777, p=0.017 \varnothing=.206)$, and almost three times more respondents in the EC buildings than in the LeG buildings said that their overall lighting quality was 'excellent' (Figure 5).

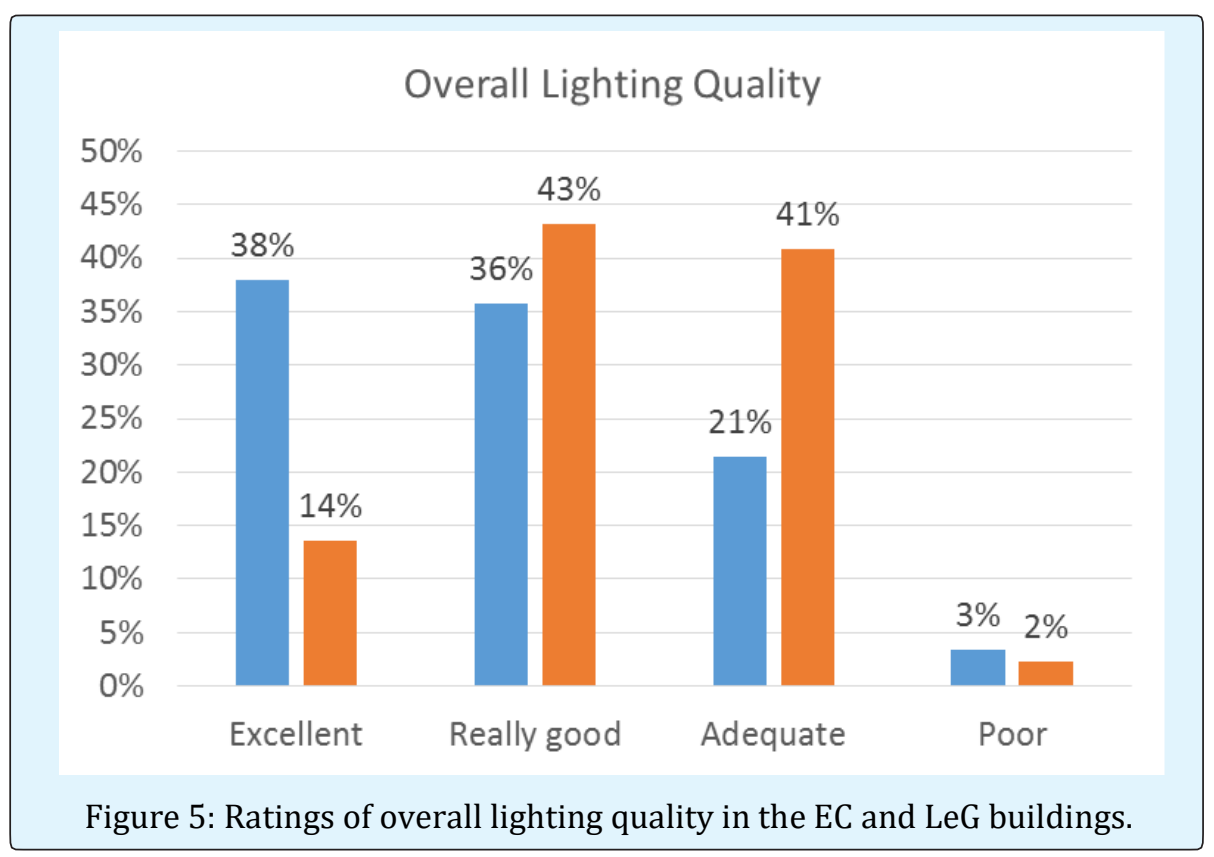




\section{Office Lighting and Eyestrain}

There was a significant difference in the frequency of experiencing eyestrain between buildings with the EC and those with LeG $(\chi 2(4, \mathrm{~N}=311)=26.947, \mathrm{p}=0.000 \varnothing=$
.282), and more workers in the LeG buildings than in the EC buildings said that they experience eyestrain (Figure 6).

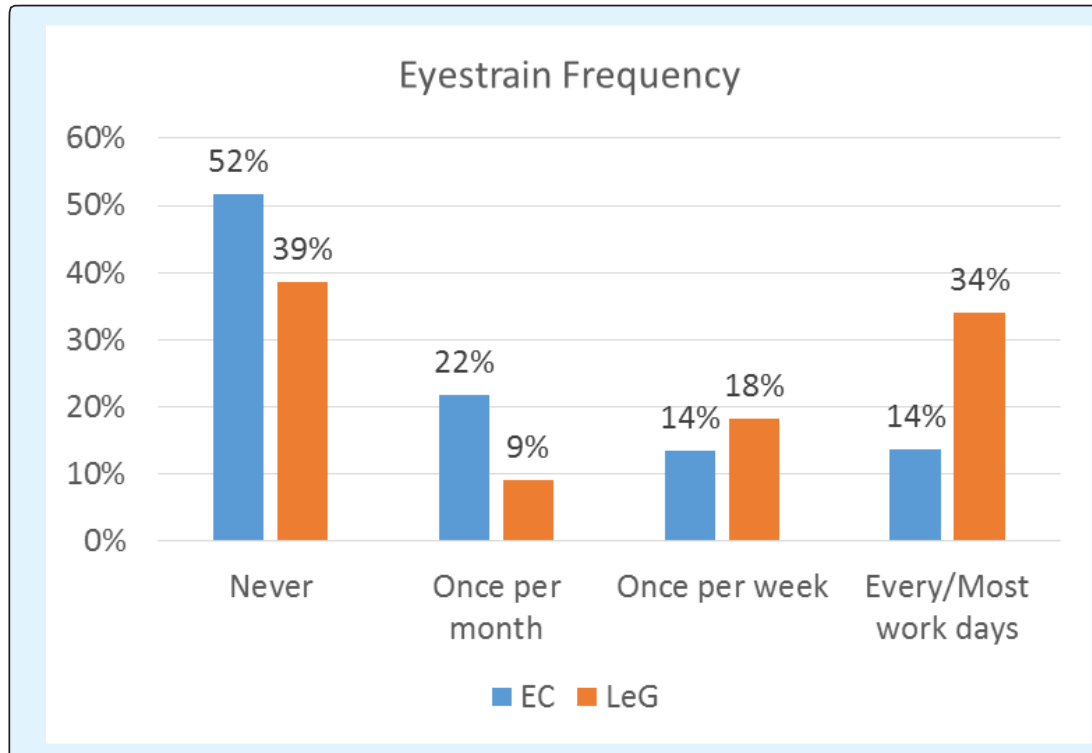

Figure 6: Frequency of experiencing eyestrain in the EC and LeG buildings.

\section{Office Lighting and Headaches}

There was a significant difference in the frequency of experiencing headaches $(\chi 2(4, \mathrm{~N}=311)=18.591, \mathrm{p}=$ $0.001 \varnothing=.238$ ), and more respondents in the EC buildings

in in the LeG buildings said that they never experience headaches (Figure 7).

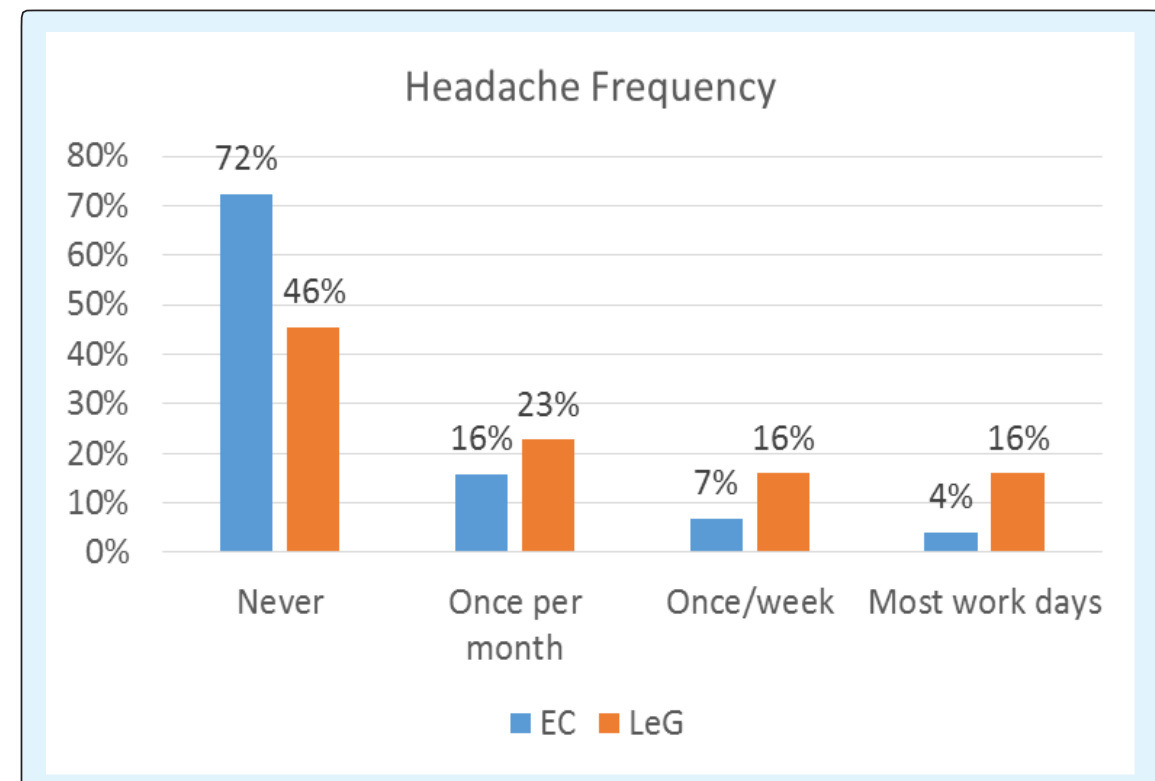

Figure 7: Frequency of experiencing headaches in the EC and LeG buildings. 


\section{Lighting Quality and Satisfaction}

Satisfaction with the quality of the lighting (daylight + artificial light) in the office was significantly different between the EC buildings and those with LeG $(\chi 2(4$,
$\mathrm{N}=310)=15.864, \mathrm{p}=0.003 \varnothing=.221$ ), and many more respondents in the EC buildings compared with those in the LeG buildings said that they were satisfied with their lighting quality (Figure 8).

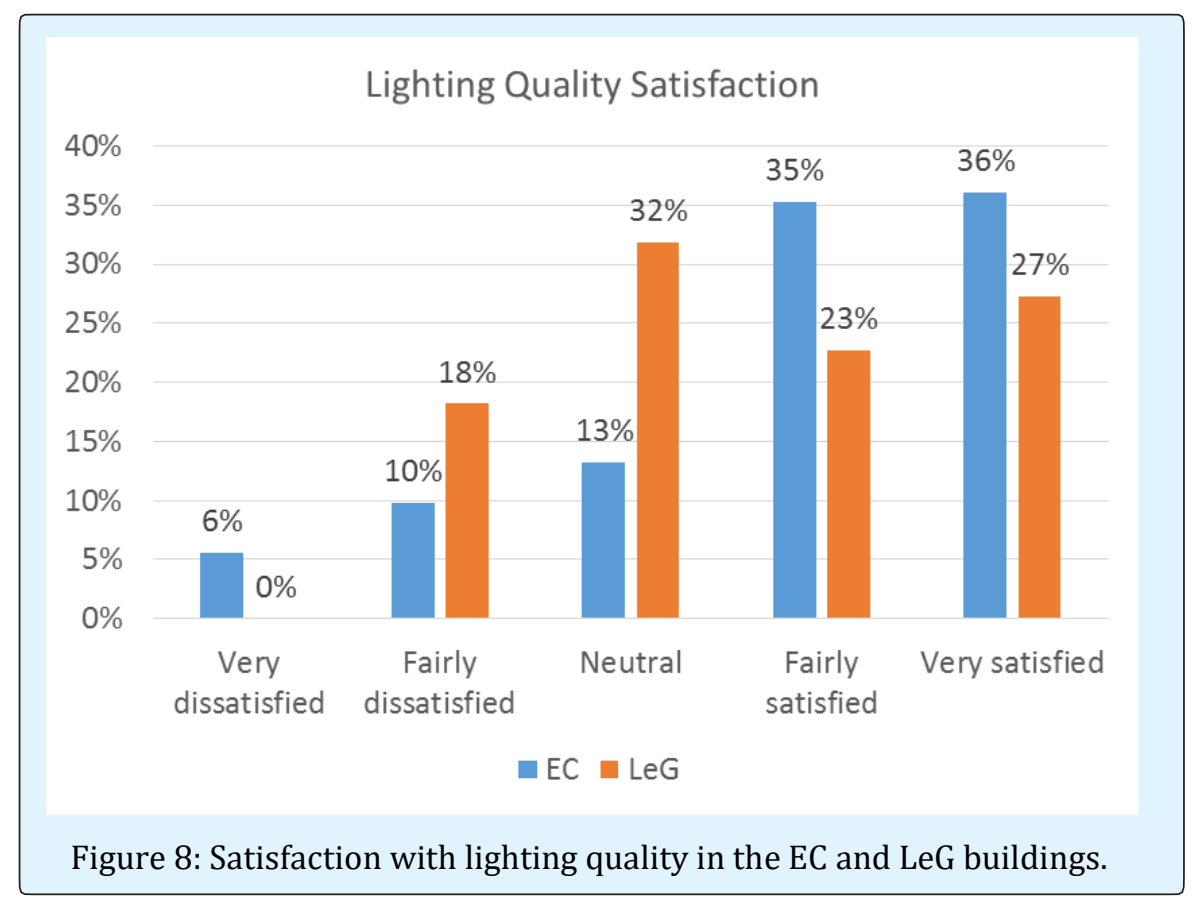

\section{Opinion of Window Glass and Lighting Quality}

Opinions on the window glass and lighting quality were significantly different between the EC and LeG buildings $(x 2(2, N=310)=23.643, p=0.000 \varnothing=266)$, and more

respondents in the EC buildings than in the LeG buildings said that the glass improves the lighting quality (Figure 9).

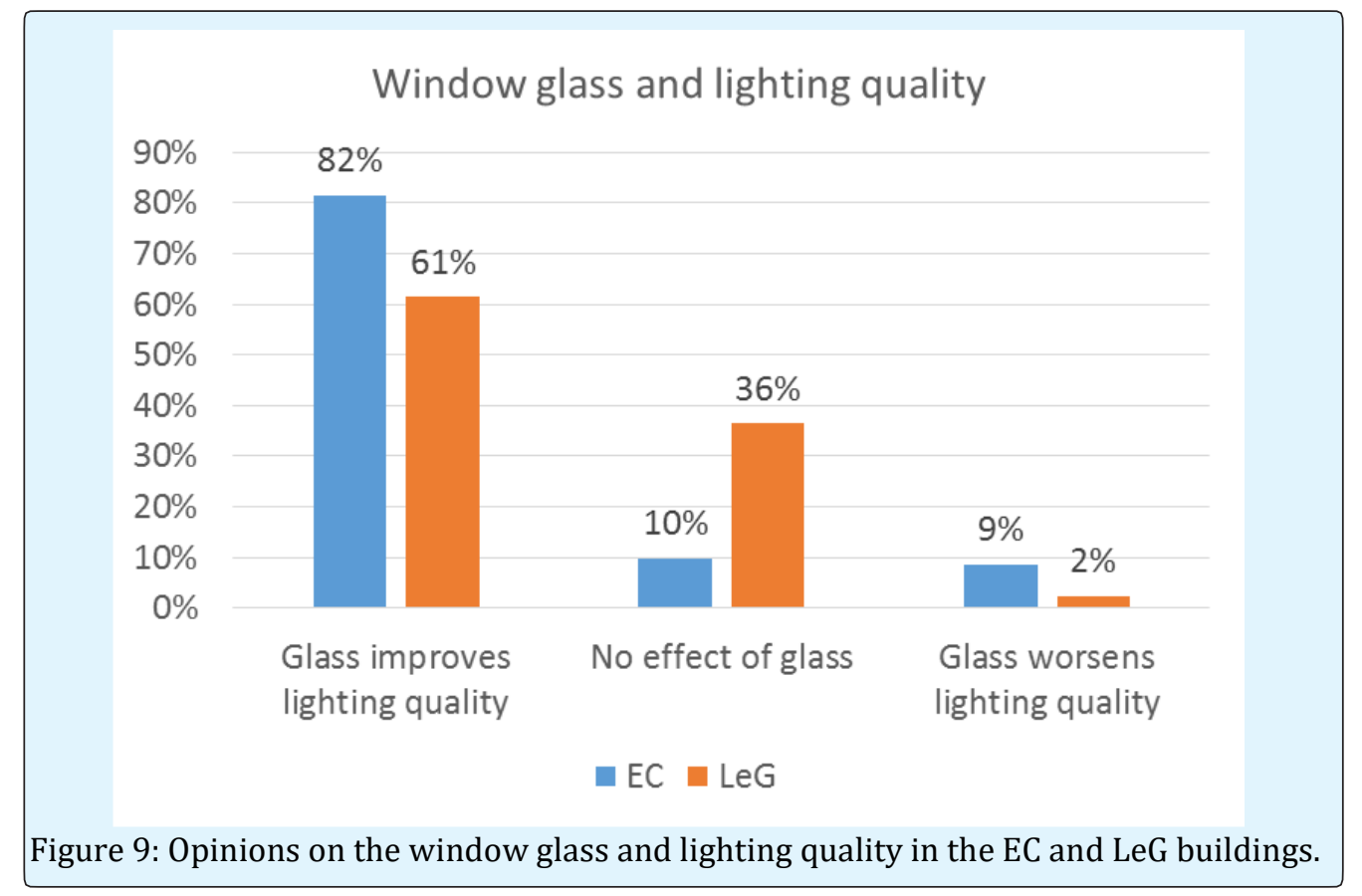




\section{Lighting and Alertness}

As predicted, the effects of lighting on alertness was significantly different between the EC and LeG buildings $(\chi 2(2, N=310)=5.979, p=0.050 \varnothing=.138)$, and fewer workers in the EC buildings said that the lighting makes them feel drowsy compared with those in the LeG buildings (Figure 10).

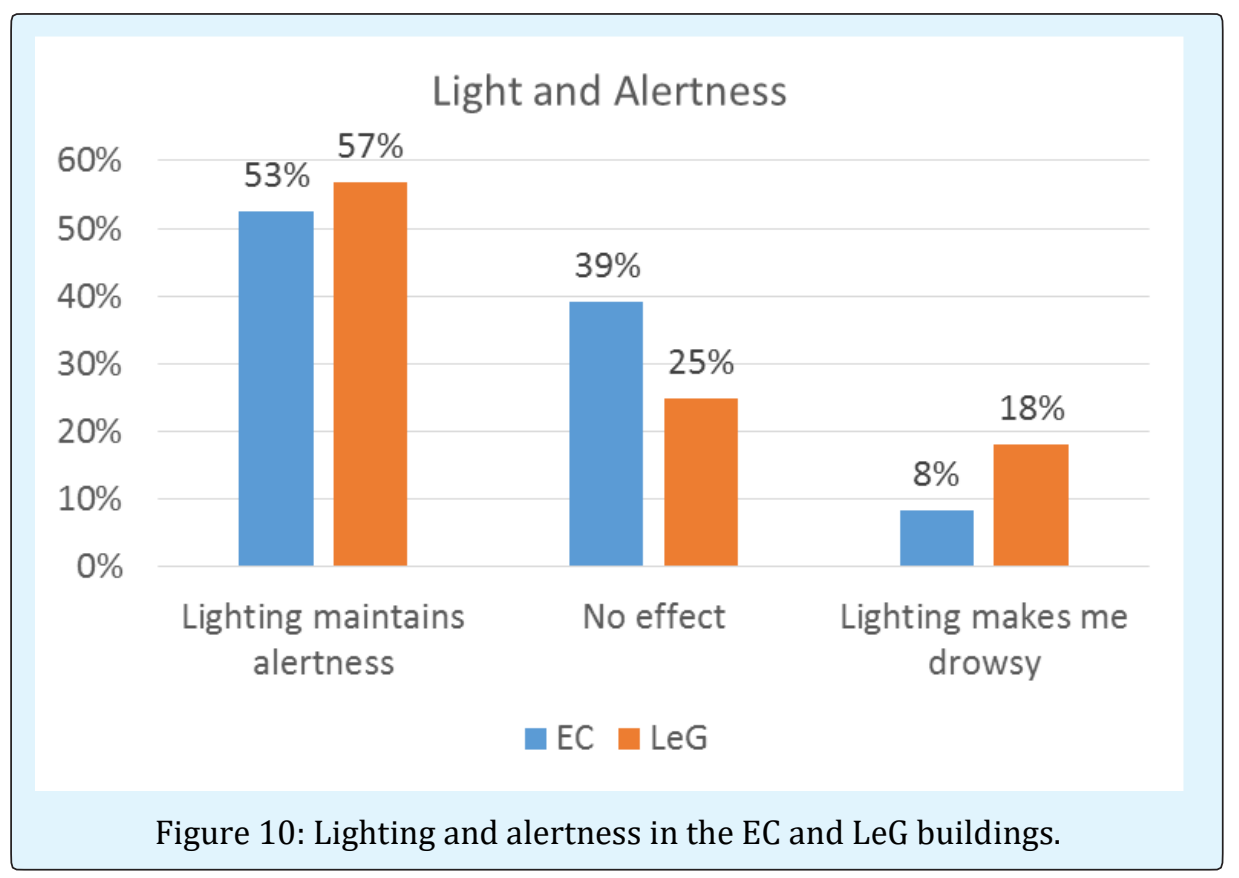

\section{Daylight Glare}

There was no significant difference between EC and LeG buildings in experiences of daylight glare. As shown in Table 3, only a small minority of respondents experienced daylight glare daily in the EC and LeG buildings.

\begin{tabular}{|c|c|c|c|c|c|}
\hline & \multicolumn{5}{|c|}{ Daylight glare frequency } \\
\cline { 2 - 6 } & Never & $\begin{array}{c}1-2 \\
\text { month }\end{array}$ & $\begin{array}{c}1-2 \\
\text { week }\end{array}$ & $\begin{array}{c}\text { Most } \\
\text { days }\end{array}$ & $\begin{array}{c}\text { Every } \\
\text { day }\end{array}$ \\
\hline $\begin{array}{c}\text { EC } \\
(\mathrm{n}=267)\end{array}$ & $49.8 \%$ & $19.5 \%$ & $14.2 \%$ & $10.9 \%$ & $5.6 \%$ \\
\hline $\begin{array}{c}\text { LeG } \\
(\mathrm{n}=44)\end{array}$ & $61.4 \%$ & $4.5 \%$ & $13.6 \%$ & $15.9 \%$ & $4.5 \%$ \\
\hline
\end{tabular}

Table 3: Respondents' reports of daylight glare by type of glass.

\section{Office Windows, Lighting Quality, Window Proximity and Productivity}

There was no significant difference in responses between buildings with the EC and those with LeG, and $65 \%$ of respondents in the EC buildings and $57 \%$ of respondents in the LeG buildings said that the windows improve lighting quality and their productivity (see Table 4).

\begin{tabular}{|c|c|c|}
\hline $\begin{array}{c}\text { Windows-lighting quality- } \\
\text { productivity }\end{array}$ & $\begin{array}{c}\text { EC } \\
(\mathbf{n = 2 6 5 )}\end{array}$ & $\begin{array}{c}\text { LeG } \\
(\mathbf{n = 4 4 )}\end{array}$ \\
\hline $\begin{array}{c}\text { Windows improve lighting and } \\
\text { productivity a lot }\end{array}$ & $35.8 \%$ & $40.9 \%$ \\
\hline $\begin{array}{c}\text { Windows improve lighting and } \\
\text { productivity a little }\end{array}$ & $29.4 \%$ & $15.9 \%$ \\
\hline Windows only improve lighting & $20.8 \%$ & $27.3 \%$ \\
\hline No effect of windows & $9.1 \%$ & $11.4 \%$ \\
\hline $\begin{array}{c}\text { Windows don't affect } \\
\text { lighting/little less productivity }\end{array}$ & $3.8 \%$ & $2.3 \%$ \\
\hline $\begin{array}{c}\text { Windows don't affect lighting/lot } \\
\text { less productivity }\end{array}$ & $1.1 \%$ & $2.3 \%$ \\
\hline
\end{tabular}

Table 4: Effects of windows and lighting quality on productivity in the EG and LeG buildings.

There was no significant difference in percentage productivity responses between buildings with the EC and those with LeG. As shown in table 5, around the same percentage of respondents said that the windows and office lighting improve productivity in the EC buildings $(62.5 \%)$ and in the LeG buildings $(50.0 \%)$. For the effects of windows and office lighting the mean percentage productivity $( \pm$ S.E.) was $1.75 \% \pm 0.14 \%$ in the EC buildings and $1.30 \% \pm 0.40 \%$ for the LeG buildings. 


\section{Ergonomics International Journal}

\begin{tabular}{|c|c|c|c|c|c|c|c|c|c|c|c|}
\hline & \multicolumn{10}{|c|}{ Percent Productivity } \\
\cline { 2 - 11 } & -5 & -4 & -3 & -2 & -1 & 0 & +1 & +2 & +3 & +4 & +5 \\
\hline $\begin{array}{c}\text { EC } \\
(\mathrm{n}=265)\end{array}$ & 0.02 & $0.4 \%$ & $1.9 \%$ & $1.5 \%$ & $2.6 \%$ & $29.1 \%$ & $7.9 \%$ & $14.3 \%$ & $14.7 \%$ & $11.3 \%$ & $14.3 \%$ \\
\hline $\begin{array}{c}\text { LeG } \\
(\mathrm{n}=44)\end{array}$ & 0.02 & $2.3 \%$ & $6.8 \%$ & $2.3 \%$ & $2.3 \%$ & $34.1 \%$ & $2.3 \%$ & $6.8 \%$ & $18.2 \%$ & $6.8 \%$ & $15.9 \%$ \\
\hline
\end{tabular}

Table 5: Effects of windows and lighting quality on percent productivity in the EC and LeG buildings.

There was no significant difference between the EC and LeG buildings for the effect of window proximity on productivity, as shown in Table 6.

\begin{tabular}{|c|c|c|}
\hline \multicolumn{3}{|c|}{ Mean \% productivity } \\
\hline Window proximity & EC & LeG \\
\hline$<10^{\prime}$ & 1.95 & 2.00 \\
\hline $10-25^{\prime}$ & 1.41 & 1.05 \\
\hline$>25^{\prime}$ & 1.43 & 1.14 \\
\hline Interior office & 1.00 & 0.00 \\
\hline
\end{tabular}

Table 6: Effects of windows proximity on percent productivity in the EC and LeG buildings.

\section{Daylight Quality and Mood}

There was no significant difference in responses between buildings with the EC and those with LeG. As shown in Table 7, around the same percentage of respondents said that the daylight quality was pleasant and made them happier in the EC buildings (84.1\%) and in the LeG buildings (88.6\%).

\begin{tabular}{|c|c|c|}
\hline Daylight and mood & $\begin{array}{c}\text { EC } \\
\text { (n=264) }\end{array}$ & $\begin{array}{c}\text { LeG } \\
\text { (n=44) }\end{array}$ \\
\hline Daylight pleasant/lot happier & $50.8 \%$ & $47.7 \%$ \\
\hline $\begin{array}{c}\text { Daylight pleasant/little } \\
\text { happier }\end{array}$ & $33.3 \%$ & $40.9 \%$ \\
\hline No effect of daylight on mood & $12.1 \%$ & $9.1 \%$ \\
\hline $\begin{array}{c}\text { Daylight annoying/little } \\
\text { worse mood }\end{array}$ & $3.4 \%$ & $0.0 \%$ \\
\hline $\begin{array}{c}\text { Daylight annoying/lot worse } \\
\text { mood }\end{array}$ & $0.4 \%$ & $2.3 \%$ \\
\hline
\end{tabular}

Table 7: Effects of daylight quality on mood in the EC and LeG buildings.

\section{Daylight Quality, Health and Wellbeing}

There was no significant difference in responses between buildings with the EC and those with LeG. As shown in table 8 , around the same percentage of respondents said that the daylight improves health in the EC buildings (72.0\%) and in the LeG buildings (85.8\%).

\begin{tabular}{|c|c|c|}
\hline Daylight-health-wellbeing & $\begin{array}{c}\text { EC } \\
(\mathbf{n = 2 4 7})\end{array}$ & $\begin{array}{c}\text { LeG } \\
(\mathbf{n = 4 4 )}\end{array}$ \\
\hline $\begin{array}{c}\text { Daylight improves health a } \\
\text { lot }\end{array}$ & $34.5 \%$ & $38.6 \%$ \\
\hline $\begin{array}{c}\text { Daylight improves health a } \\
\text { little }\end{array}$ & $37.5 \%$ & $47.7 \%$ \\
\hline No effect of daylight & $24.3 \%$ & $11.4 \%$ \\
\hline $\begin{array}{c}\text { Daylight worsens health a } \\
\text { little }\end{array}$ & $3.7 \%$ & $2.3 \%$ \\
\hline
\end{tabular}

Table 8: Effects of daylight quality on health and wellbeing in the EC and LeG buildings.

\section{Daylight Quality and Energy}

There was no significant difference in responses between buildings with the EC and those with LeG. As shown in table 9, most respondents said that the daylight increases their energy level in the EC buildings (67.3\%) and in the LeG buildings (68.2\%).

\begin{tabular}{|c|c|c|}
\hline Daylight - energy level & EC (n=266) & LeG (n=44) \\
\hline Lot more energy & $23.3 \%$ & $25.0 \%$ \\
\hline Little more energy & $44.0 \%$ & $43.2 \%$ \\
\hline No effect on energy & $26.7 \%$ & $25.0 \%$ \\
\hline Little less energy & $5.3 \%$ & $4.5 \%$ \\
\hline Lot less energy & $0.8 \%$ & $2.3 \%$ \\
\hline
\end{tabular}

Table 9: Daylight quality and energy level in the EC and LeG buildings.

\section{Daylight Quality and Work Quality}

There was no significant difference in responses between buildings with the EC and those with LeG. As shown in table 10, most respondents said that the daylight quality improves their work quality in the EC buildings (57.5\%) and in the LeG buildings (72.8\%). 


\begin{tabular}{|c|c|c|}
\hline $\begin{array}{c}\text { Daylight and work } \\
\text { quality }\end{array}$ & $\begin{array}{c}\text { EC } \\
\text { (n=266) }\end{array}$ & $\begin{array}{c}\text { LeG } \\
\text { (n=44)\% }\end{array}$ \\
\hline $\begin{array}{c}\text { Work quality improved a } \\
\text { lot }\end{array}$ & $18.4 \%$ & $27.3 \%$ \\
\hline $\begin{array}{c}\text { Work quality improved a } \\
\text { little }\end{array}$ & $39.1 \%$ & $45.5 \%$ \\
\hline No effect & $39.1 \%$ & $22.7 \%$ \\
\hline Work quality a little worse & $3.4 \%$ & $4.5 \%$ \\
\hline
\end{tabular}

Table 10: Daylight quality and work quality in the EC and LeG buildings.

\section{Office Lighting Quality and Visual Comfort}

There was no significant difference in responses between buildings with the EC and those with LeG (Table 11) and most respondents said that the office lighting quality was comfortable in the EC buildings $(80.6 \%)$ and in the LeG buildings (63.6\%).

\begin{tabular}{|c|c|c|}
\hline $\begin{array}{c}\text { Office lighting quality and } \\
\text { visual comfort }\end{array}$ & $\begin{array}{c}\text { EC } \\
(\mathbf{n = 2 6 7 )}\end{array}$ & $\begin{array}{c}\text { LeG } \\
(\mathbf{n = 4 4 )}\end{array}$ \\
\hline Very comfortable & $44.6 \%$ & $34.1 \%$ \\
\hline Fairly comfortable & $36.0 \%$ & $29.5 \%$ \\
\hline Neutral & $12.0 \%$ & $25.0 \%$ \\
\hline Fairly uncomfortable & $6.0 \%$ & $9.1 \%$ \\
\hline Very uncomfortable & $1.5 \%$ & $2.3 \%$ \\
\hline
\end{tabular}

Table 11: Office lighting quality and visual comfort in the EC and LeG buildings.

\section{Opinion of Window Glass in Current and Previous Offices}

Only the workers in the EC buildings were asked "How do you compare the window glass in your current office with that in your previous office?" As shown in table 12, there was a strong preference for the current glass in the EC buildings (70.7\%).

\begin{tabular}{|c|c|}
\hline Window glass preference & EC $(\mathbf{n = 2 4 2 )}$ \\
\hline Prefer current glass & $70.7 \%$ \\
\hline No preference & $14.5 \%$ \\
\hline Prefer other glass & $9.5 \%$ \\
\hline Not worked elsewhere & $5.4 \%$ \\
\hline
\end{tabular}

Table 12: Opinions on the window glass in current and previous offices in the EC buildings.

\section{EC Buildings Opinions}

Workers in the EC buildings were asked "How do you feel about working in your office and in this office building?", and many respondents said that they felt excited to be working in their EC buildings, that they felt proud of their building and that the EC helps to create a more productive and healthier workplace.

\begin{tabular}{|c|c|}
\hline I feel excited to work in this building & $65.6 \%$ \\
\hline I feel proud to work in this building & $54.6 \%$ \\
\hline $\begin{array}{c}\text { The glass in this building helps to create a } \\
\text { more productive work environment }\end{array}$ & $39.6 \%$ \\
\hline $\begin{array}{c}\text { The glass in this building helps to create a } \\
\text { healthier work environment }\end{array}$ & $38.8 \%$ \\
\hline $\begin{array}{c}\text { I would recommend working in this building } \\
\text { to others }\end{array}$ & $33.9 \%$ \\
\hline I feel relaxed when I work in this building & $10.1 \%$ \\
\hline
\end{tabular}

Table 13: Respondents' opinions about working in the EC buildings $(\mathrm{n}=227)$.

\section{Discussion}

Many studies of the effects of lighting employ shortterm laboratory experimental exposures. However, unless the anticipated lighting variable has an acute effect such short-term studies may fail to reveal the effects of longer term exposures. An analogous situation might be determining the efficacy of an antibiotic, where an effect seldom is seen after a single dose but rather requires repeated doses over time for maximum efficacy. Consequently, field experimental and comparative lighting studies in real-world settings often can reveal more subtle effects that may be potentially masked in a short-term laboratory exposure.

The present comparative field survey of workers in office buildings with EC or with LeG revealed several significant results. In the EC buildings, more workers sat closer to the windows than in the LeG offices, and consequently, more workers reported sun views, better daylight quality, and better overall lighting quality. EC is designed to allow an outside view but to minimize any glare issues, and the survey results showed that there was no difference in reports of glare between the EC buildings, where many more workers sat close to the windows, and the LeG offices where they sat further from the windows and fewer had a sun view. This suggests that the EC was working as designed to minimize glare while blocking the heat without compromising an outdoor view. 


\section{Ergonomics International Journal}

In future research, it would be useful to collect data on the performance of the EC windows and data on the collect data on the use of any blinds in the LeG buildings to further test this possible explanation of the survey results

There was a significantly lower prevalence of eyestrain and headache complaints, both symptoms of CVS, along with higher levels of satisfaction with lighting quality and positive opinions of how the windows improved lighting quality in the EC buildings. As noted by Blehm et al. [13] CVS, which in 2005 was a $\$ 2$ billion problem, the causes can be multifactorial, but they definitely include lighting, glare, and screen display design characteristics. The present study only collected survey responses and lighting and glare issues, and future research should try to gather objective measures of glare and also examine screen design characteristics for a more complete picture of how EC beneficial reduces CVS risks.

As noted in the introduction, there is a growing literature on the beneficial effects of blue enriched light exposure on alertness and cognition [17,19-22]. Previous research has found that blue light improves alertness and the present study also found that workers in the EC buildings reported significantly less drowsiness and greater alertness, and this may be because of the blue light that is transmitted through the EC even in its darkest tint state. However, several previous studies have evaluated enhanced blue light for workers on shifts, whereas the present research only addressed daytime working. In section 54 (Circadian Lighting Design) of the WELL V2 building performance system it is emphasized that "the biological effects of light on humans can be measured in Equivalent Melanopic Lux (EML)" [17,25,26]. Future research should objectively measure the blue light component to see the effects of EC on the EML and whether this could be the reason for the alertness finding.

Similar opinions were recorded from workers in the EC and LeG buildings for reports of daylight glare, effects of windows on lighting quality and productivity, mood, health and well-being, energy, and improvements in work quality. This may either indicate an equivalence between the buildings or more likely it indicates a limitation of the research design because workers in the EC mostly had prior experience of buildings with LeG and consequently they were able to provide comparative judgments of their EC experience compared with their prior experiences, whereas workers in the LeG had no experience of the EC environment.

Consequently, they may have interpreted some of the questions as being more general and they may have responded more generally to questions about say "the importance of daylight". However, workers in the EC buildings did voice positive opinions about the quality co the visual environment with EC.

There are other limitations with the current research. Worker samples were self-selected and sample sizes were uneven. From the survey it wasn't possible to know the precise content of their work in terms of its visual demands which could be affected by windows and daylight. Objective measures of the visual environment were not available (e.g. illuminance levels, variations in the transmittance of the EC). Objective measures of work performance were not available. Consequently, although the present study shows several favorable results for the $\mathrm{EC}$, these should not be interpreted as definitive findings until further research has been undertaken.

Future studies could usefully compare the potential benefits of EC in both pre-installation and postinstallation surveys of workers in the same organization. Studies could also comparatively evaluate the performance of workers in EC and LeG buildings over longer timeframes and with more detailed information on where respondents work in a building and what their lighting exposures are over time.

Previous research has shown the benefits of EC for reducing the energy requirements for office buildings [15]. Limitations apart, the present study shows that EC can improve the visual environment to improve the satisfaction of workers, reduce the prevalence of CVS symptoms, and foster positive feelings about their visual environment at work.

\section{Acknowledgement}

We thank the participating companies and their employees and View Inc. for their support in with this research project.

\section{References}

1. USGBC (2018) Better buildings are our Legacy. US Green Building Council.

2. USGBC (2018) Daylight.

3. IWBI (2018) International WELL: buildings. Welcome to WELL V2.

4. Le Gates TA, Fernandez DC, Hattar S (2014) Light as a central modulator of circadian rhythms, sleep and affect. Nature Reviews Neuroscience 15(7): 443-454. 


\section{Ergonomics International Journal}

5. Boyce PR, Hunter C, Howlett H (2003) The benefits of daylight through windows. Lighting Research Center, Norway.

6. Czeisler CA, Duffy JF, Shanahan TL, Brown EN, Mitchell JF, et al. (1999) Stability, precision, and near24-hour period of the human circadian pacemaker. Science 284(5423): 2177-2181.

7. Ulrich RS (1984) View through a window may influence recovery from surgery. Science 224 (4647): 420-421.

8. Korpela K., De Bloom J, Kinnunen U (2015) From restorative environments to restoration in work. Intelligent Buildings International 7(4): 215-223.

9. Heschong L (2003) Windows and offices: A study of office worker performance and the indoor environment. CHeschong Mahone Group, Fair Oaks.

10. Leather P, Pyrgas M, Beale D, Lawrence C (1998) Windows in the workplace: Sunlight, view, and occupational stress. Environment and Behavior 30(6): 739-762.

11. Aries MBC (2005) Human lighting demands - Healthy lighting in an office environment. Eindhoven the Netherlands, Eindhoven University of Technology.

12. Robinson A, Selkowitz S (2013) Tips for Day lighting with Windows. Ernest Orlando Lawrence Berkeley National Laboratory, Environmental Energy Technology Division.

13. Blehm C, Vishnu S, Khattak A, Mitra S, Yee RW (2005) Computer vision syndrome: A review. Survey of Opthalmology 50(3): 253-262.

14. AOA (2018) Computer Vision Syndrome. American Optometric Association.

15. Khowal D, Gubiotti T, Smith C (2016) Analysis of dynamic glass for patient satisfaction and energy savings improvements in a hospital environment, White Paper, View Inc. CA 95035, USA.
16. Do M, Tri H, Yau K (2010) Intrinsically Photosensitive Retinal Ganglion Cells. Physiological Reviews 90 (4): 1547-1581.

17. Mills PR, Tomkins SC, Schlangen LJM (2007) The effect of high correlated colour temperature office lighting on employee wellbeing and work performance. Journal of Circadian Rhythms 5: 2 .

18. Plitnick B, Figueiro MG, Wood B, Rea MS (2010) The effects of red and blue light on alertness and mood at night. Lighting Research \& Technology 42(4): 449458.

19. Alkozei A, Smith R, Dailey NS, Bajaj S, Killgore WDS (2017) Acute exposure to blue wavelength light during memory consolidation improves verbal memory performance. PLOS ONE 12(9): e0184884.

20. Chellappa SL, Steiner R, Blattner P, Oelhafen P, Götz T, et al. (2011) Non-visual effects of light on melatonin, alertness and cognitive performance: can blueenriched light keep us alert? PLOS ONE 6(1): e16429.

21. Beaven CM, Ekström J (2013) A Comparison of Blue Light and Caffeine Effects on Cognitive Function and Alertness in Humans. PLOS ONE 8(10): e76707.

22. Ekström JG, Beaven CM (2014) Effects of blue light and caffeine on mood. Psychopharmacology 231(18): 3677-3683.

23. Baek H, Min BK (2015) Blue light aids in coping with the post-lunch dip: an EEG study. Ergonomics 58(5): 803-810.

24. Hedge A, Nou D (2018) Effects of Electrochromic Glass on Computer Vision Syndrome. Proceedings of the Human Factors and Ergonomics Society, Santa Monica.

25. International WELL Building Institute (2018) The WELL Building Standard.

26. WELL (2018) Circadian Lighting Design. 